\title{
Schizophrenia and violence: study in a general psychiatric hospital with HCR-20 and MOAS
}

\author{
Esquizofrenia e violência: estudo em um hospital psiquiátrico clínico com o \\ HCR-20 e a MOAS
}

\author{
Leonardo Fernandez Meyer, ${ }^{1,2}$ Lisieux E. de Borba Telles, ${ }^{3,4}$ Kátia Mecler, ${ }^{2}$ Ana Luiza Alfaya Galego Soares, ${ }^{5}$ \\ Renata Santos Alves, ${ }^{2,6}$ Alexandre Martins Valença ${ }^{1,7}$
}

\begin{abstract}
Objective: This preliminary study aimed to identify and compare characteristics related to violent behavior in inpatients with schizophrenia at a general psychiatric hospital using the Historical, Clinical, and Risk Management 20 (HCR-20), the Modified Overt Aggression Scale (MOAS), and sociodemographic data.

Method: Violent and nonviolent participants were selected based on psychiatric admission reports. Participants with reports of aggressive behavior and HCR-20 total score $\geq 21$ upon admission were assigned to the violent patient group. Participants without aggressive behavior and with HCR-20 total score $<21$ upon admission were assigned to the nonviolent patient group. The MOAS was applied to characterize the degree of severity of the violent behavior.

Results: HCR-20 and its subscales were effective in differentiating between the violent and nonviolent participant groups. Twelve of the 20 HCR-20 items were useful for distinguishing between the groups, although total HCR-20 scores were more reliable when applied to the nonviolent patient group. The MOAS did not show high degrees of severity for the types of aggression observed in the participants.

Conclusion: HCR-20 was useful and reliable for distinguishing between violent and nonviolent patients with schizophrenia in this clinical psychiatric setting. Item analysis identified the most relevant characteristics in each group. The use of the HCR-20 in clinical psychiatric settings should be encouraged.
\end{abstract}

Keywords: Aggressiveness, psychosis, schizophrenia, HCR-20, risk assessment, MOAS.

\section{Resumo}

Objetivo: Este estudo preliminar tem por objetivo identificar e comparar características relacionadas ao comportamento violento em pacientes com esquizofrenia internados em um hospital psiquiátrico utilizando o Historical, Clinical, and Risk Management 20 (HCR-20), a Modified Overt Aggression Scale (MOAS), e dados sociodemográficos.

Método: Foram selecionados participantes com e sem histórico de comportamento violento, referidos nos relatórios de internação hospitalar. Participantes violentos e com escore total do HCR-20 $\geq 21$ na internação foram selecionados para o grupo violento. Participantes não violentos com escore total do HCR-20 < 21 na internação foram selecionados para o grupo não violento. A MOAS foi aplicada para caracterizar o grau de severidade do comportamento violento.

Resultados: O HCR-20 e suas subescalas foram eficazes na diferenciação entre os participantes dos grupos. Doze dos 20 itens do HCR-20 foram úteis na diferenciação entre os grupos, apesar do escore total do HCR-20 ter sido mais confiável quando aplicado ao grupo não violento. A MOAS não apresentou graus de severidade elevados para os tipos de agressividade observados nos participantes.

Conclusão: O HCR-20 foi útil e confiável na distinção entre pacientes esquizofrênicos violentos e não violentos em ambiente psiquiátrico clínico, já que a análise dos itens identificou as características mais relevantes em cada grupo. O uso do HCR-20 em ambientes psiquiátricos clínicos deveria ser encorajado.

Descritores: Agressividade, psicose, esquizofrenia, HCR-20, avaliação de risco, MOAS.

\footnotetext{
${ }^{1}$ Instituto de Psiquiatria (IPUB), Universidade Federal do Rio de Janeiro (UFRJ), Rio de Janeiro, RJ, Brazil. ${ }^{2}$ Instituto de Perícias Heitor Carrilho (IPHC), Rio de Janeiro, RJ, Brazil. ${ }^{3}$ Departamento de Psiquiatria, Universidade Federal do Rio Grande do Sul (UFRGS), Porto Alegre, RS, Brazil. ${ }^{4}$ Instituto de Psiquiátrico-Forense Dr. Maurício Cardoso (IPF), Porto Alegre, RS, Brazil. ${ }^{5}$ Divisão de Saúde do Trabalhador (DVST), UFRJ, Rio de Janeiro, RJ, Brazil. ${ }^{6}$ Departamento de Medicina, Universidade Estácio de Sá (UES), Rio de Janeiro, RJ, Brazil. ${ }^{7}$ Departamento de Psiquiatria, Universidade Federal Fluminense (UFF), Niterói, RJ, Brazil. Submitted Apr 01 2017, accepted for publication Feb 272018.

Suggested citation: Meyer LF, Telles LEB, Mecler K, Soares ALAG, Alves RS, Valença AM. Schizophrenia and violence: study in a general psychiatric hospital with HCR-20 and MOAS. Trends Psychiatry Psychother. 2018;40(4):310-317. http://dx.doi.org/10.1590/2237-6089-2017-0039
} 


\section{Introduction}

Psychotic disorders have been consistently associated with aggressive behavior. ${ }^{1-3}$ Violence risk assessment (VRA) began in forensic psychiatry, used especially for verifying cessation of dangerousness. ${ }^{1,3}$ Such assessment was originally based on clinical psychiatric examination, and a number of scientific advances have been made since the 1990 s in complementing traditional VRA. ${ }^{1,2,4}$

The development of psychometric instruments such as the Historical, Clinical, and Risk Management-20 scale (HCR-20) is important for reducing evaluation bias, since objective violence-related parameters are traditionally stablished and evaluated through clinical examination in the mentally ill. 1,2,4 Regarding psychiatric diagnosis, the available evidence suggests that HCR-20 is more effective in schizophrenia and mental retardation than in affective and personality disorders. ${ }^{5,6}$

The main objective of VRA in psychiatric patients is the identification of characteristics specifically related to violent behavior and the planning and implementation of therapeutic strategies aimed at reducing that specific risk. ${ }^{1,2}$ The HCR-20 was first developed especially for VRA in forensic psychiatric patients. Later research also showed the instrument's validity in mentally ill patients in general. ${ }^{2}$ Subsequent research with psychiatric patients demonstrated the instrument's reliability in this population. ${ }^{5,7}$

Clinical psychiatrists are frequently asked to issue reports, perform assessments, and make judgment calls regarding potentially aggressive patients. Psychometric instruments such as HCR-20 in clinical practice (especially in psychiatric emergency settings) can thus be useful for identifying the risk of violence and thereby offering appropriate treatment for these individuals.

Most empirical studies on VRA focus on individuals who are not guilty by reason of insanity (NGRI). ${ }^{7-}$ 16 These are defendants with a diagnosis of mental disorder, i.e., not able to appreciate the nature (quality) of their act or to have self-control at the time of the offense. Consequently, the characteristics of the general psychiatric population with regard to aggressiveness and the HCR-20 remain partially unknown..$^{4,5}$

The aim of this article was to assess and compare characteristics related to violence, using the HCR-20, in patients with schizophrenia admitted to a general psychiatric hospital, with and without aggressive behavior at the time of admission.

\section{Method}

The study adopted a cross-sectional design. One trained researcher (first author) was responsible for applying the selected scales. In this study, aggressive behavior was defined as violent acts towards others, either witnessed or recorded in medical reports (current admission).

We used clinical criteria (presence or absence of aggressive behavior as cause for current psychiatric admission) and HCR-20 scores to divide the total sample into two groups, violent and nonviolent. We also used HCR-20 scores and other psychometric instruments to compare the characteristics of the two groups.

Participants considered aggressive according to clinical criteria and scoring $\geq 21$ on HCR-20 formed the violent group. Those considered nonaggressive according to clinical criteria and scoring $\leq 20$ on HCR-20 formed the nonviolent group. We adopted this score as the cutoff point because the only Brazilian study involving patients with mental disorders and the HCR-20 found a similar value. ${ }^{15}$ The Modified Overt Aggression Scale (MOAS) was used to describe the aggressive behavior. Both instruments are discussed in detail below.

\section{Sample}

Inpatients at a general psychiatric hospital diagnosed with schizophrenia according to the Diagnostic and Statistical Manual of Mental Disorders, Fourth Edition, Text Revision (DSM-IV-TR), ${ }^{17}$ were selected between April and September 2014.

Inclusion criteria were age between 18 and 60 years, male gender, diagnosis of schizophrenia (Structured Clinical Interview for DSM-IV Axis I Disorders SCID-I), ${ }^{18}$ no psychiatric comorbidity (except for substance use disorders, which are strongly related to aggressive behavior), and availability of relatives able to properly inform the patient's status. All participants were examined and their relatives interviewed by phone. Current and previous hospital files were examined.

Exclusion criteria were current or previous diagnosis of mental disorders other than schizophrenia and substance use disorders, impossibility of examination or refusal to participate, insufficient data to complete the questionnaires, and lack of family members available to properly inform the patient's status.

The local institutional review board approved the study, and the administration of the selected hospital (Centro Psiquiátrico do Rio de Janeiro - CPRJ) authorized the study. This institution offers inpatient treatment for acute psychiatric disorders. All participants signed the mandatory informed consent form.

\section{Instruments}

Historical, Clinical, and Risk Management-20 (HCR-20)

HCR-20 is a psychometric scale originally developed for VRA in mentally ill patients in forensic settings. ${ }^{2}$ 
It has also been validated for use in the general psychiatric population. $4,5 \mathrm{HCR}-20$ is divided into three subscales: Historical (10 items), Clinical (5 items), and Risk Management ( 5 items). Each item is scored as 0 (characteristic absent), 1 (characteristic partially present), or 2 (characteristic present). These subscales cover three different moments of the patient's evolution: past (Historical), present (Clinical), and future (Risk Management). The risk of violence is evaluated as low, medium, or high. ${ }^{2}$ This instrument does not have a cutoff point to identify violent behavior: the final score should be contextualized individually.

\section{Modified Overt Aggression Scale (MOAS)}

MOAS is the modified version of the Overt Aggression Scale (OAS), used to characterize observed aggressive behavior. MOAS explores the patient's behavior up to seven days prior to application of the scale. The instrument is divided into four subscales: verbal aggression, aggression against property, selfaggression, and aggression against others. Subscores correlate directly with the degree of severity in the different subtypes of aggressive behavior analyzed. ${ }^{19}$ We used MOAS to identify types of aggressive behavior, as in previous studies. ${ }^{20,21}$

\section{Setting}

The research was conducted at $C P R J$, one of the four public psychiatric emergency hospitals in the city, responsible for outpatient psychiatric care of nearby residents. Inpatient care is limited to short-term admission of acute psychiatric patients.

\section{Statistical analysis}

The Mann-Whitney nonparametric test was used, since the sample distribution was non-normal. The test was used to analyze the association between HCR20 scores (including subscales) and aggressiveness. The Student $t$-test was used to analyze and compare the distribution of HCR-20 items in the two groups. Sociodemographic data were analyzed and compared using the $t$-test (bootstrap, $\mathrm{n}=10,000$ ).

\section{Results}

The final sample consisted of 38 male participants with a diagnosis of schizophrenia; 19 were classified as violent and 19 as nonviolent.

Table 1 provides a detailed analysis of HCR-20 total and subtotal scores and the frequency distribution of

Table 1 - HCR-20 statistical description

\begin{tabular}{|c|c|c|c|c|c|}
\hline & Absent & $\begin{array}{c}\text { Partially } \\
\text { present }\end{array}$ & Present & Mean & $\begin{array}{l}\text { Standard } \\
\text { deviation }\end{array}$ \\
\hline H1 (Previous violence) & 14 & 3 & 21 & 1.18 & 0.95 \\
\hline $\mathrm{H} 2$ (Young age at first violent incident) & 25 & 4 & 9 & 0.58 & 0.86 \\
\hline H3 (Relationship instability) & 17 & 13 & 8 & 0.76 & 0.79 \\
\hline H4 (Employment problems) & 12 & 6 & 20 & 1.21 & 0.91 \\
\hline H5 (Substance use problems) & 18 & 11 & 9 & 0.76 & 0.82 \\
\hline H6 (Major mental illness) & 0 & 0 & 38 & 2.00 & 0.00 \\
\hline H7 (Psychopathy) & 33 & 4 & 1 & 0.16 & 0.44 \\
\hline H8 (Early maladjustment) & 30 & 8 & 0 & 0.21 & 0.41 \\
\hline H9 (Personality disorder) & 37 & 1 & 0 & 0.03 & 0.16 \\
\hline H10 (Prior supervision failure) & 3 & 3 & 32 & 1.76 & 0.59 \\
\hline Total Historical & & & & 8.61 & 3.48 \\
\hline C1 (Lack of insight) & 4 & 18 & 16 & 1.32 & 0.66 \\
\hline C2 (Negative attitudes) & 8 & 16 & 14 & 1.16 & 0.75 \\
\hline C3 (Active symptoms) & 0 & 0 & 38 & 2.00 & 0.00 \\
\hline C4 (Impulsivity) & 13 & 9 & 16 & 1.08 & 0.88 \\
\hline C5 (Unresponsive to treatment) & 29 & 7 & 2 & 0.29 & 0.57 \\
\hline Total Clinical & & & & 5.74 & 1.91 \\
\hline R1 (Plans lack feasibility) & 14 & 15 & 9 & 0.87 & 0.78 \\
\hline R2 (Exposure to destabilizers) & 3 & 19 & 16 & 1.34 & 0.63 \\
\hline R3 (Lack of personal support) & 22 & 12 & 4 & 0.53 & 0.69 \\
\hline R4 (Non-compliance with remediation attempts) & 9 & 17 & 12 & 1.08 & 0.75 \\
\hline R5 (Stress) & 11 & 17 & 10 & 0.97 & 0.75 \\
\hline Total Risk Management & & & & 4.79 & 2.18 \\
\hline Total HCR-20 & & & & 19.13 & 6.67 \\
\hline
\end{tabular}

HCR-20 = Historical, Clinical, and Risk Management 20. 
each item's score in the entire sample. Table 2 contains HCR-20 mean scores and subscores, divided by groups. Table 3 shows the frequency distribution of HCR-20 items in each group.

The mean \pm standard deviation total HCR-20 score considering both groups was $19.13 \pm 6.67$, close to the cutoff point established (21). The Historical, Clinical, and Risk Management subscales showed mean scores in both groups of $8.61 \pm 3.48,5.74 \pm 1.91$, and $4.79 \pm 2.18$, respectively (Table 1 ).

The total HCR-20 score and the Historical subscale showed satisfactory internal consistency, with Cronbach's alpha values (a) of 0.82 (very good) and 0.73 (good), respectively. In the Historical subscale, $\mathrm{H} 1$ (previous violence), $\mathrm{H} 2$ (young age at first violent incident), $\mathrm{H} 3$ (relationship instability), and H5 (substance use problems) were the items that differed most significantly between the two groups ( $p<0.001$ ) (Table 3); differences in items $\mathrm{H} 7$ (psychopathy) and $\mathrm{H} 8$ (early maladjustment) were also statistically significant $(p<0.05)$ (Tables 2 and 3). Item $\mathrm{H} 6$ (major mental illness) showed the same score in both groups (Tables 2 and 3 ).

The Clinical subscale showed insufficient internal consistency ( $a=0.33$ ). However, the suppression of item C5 (unresponsive to treatment) would have led to an acceptable value for the parameter $(a=0.66)$. Item C4 (impulsivity) scored differently between the groups and showed the highest statistical significance ( $p<$ 0.001) among all HCR-20 items (Table 3). Regarding items C1 (lack of insight) and C2 (negative attitudes), the differences in scores were also statistically significant $(p<0.05)$ (Table 3). Item C3 (active symptoms of major mental illness) showed the same score (2) in all participants (Tables 2 and 3).

Finally, the Risk Management subscale showed $a=0.57$ (poor), and no item exclusion would have resulted in a higher coefficient. Statistical significance was higher for item R5 (stress) ( $p<0.001$ ), followed by R1 (plans lack feasibility) and R3 (lack of personal support) $(p<0.05)$ (Table 3 ).

Table 2 - Violent behavior and HCR-20 scores, by group

\begin{tabular}{|c|c|c|c|c|}
\hline & & & & \\
\hline & Mean & SD & Mean & SD \\
\hline H1 (Previous violence) & 0.53 & 0.84 & 1.84 & 0.50 \\
\hline $\mathrm{H} 2$ (Young age at first violent incident) & 0.11 & 0.32 & 1.05 & 0.97 \\
\hline H3 (Relationship instability) & 0.32 & 0.48 & 1.21 & 0.79 \\
\hline H4 (Employment problems) & 1.05 & 0.85 & 1.37 & 0.96 \\
\hline H5 (Substance use problems) & 0.42 & 0.69 & 1.11 & 0.81 \\
\hline H6 (Major mental illness) & 2.00 & 0.00 & 2.00 & 0.00 \\
\hline H7 (Psychopathy) & 0.00 & 0.00 & 0.32 & 0.58 \\
\hline H8 (Early maladjustment) & 0.05 & 0.23 & 0.37 & 0.50 \\
\hline H9 (Personality disorder) & 0.00 & 0.00 & 0.05 & 0.23 \\
\hline H10 (Prior supervision failure) & 1.53 & 0.77 & 2.00 & 0.00 \\
\hline Total Historical* & 5.89 & 1.85 & 11.32 & 2.45 \\
\hline C1 (Lack of insight) & 1.05 & 0.71 & 1.58 & 0.51 \\
\hline C2 (Negative attitudes) & 0.79 & 0.71 & 1.53 & 0.61 \\
\hline C3 (Active symptoms) & 2.00 & 0.00 & 2.00 & 0.00 \\
\hline C4 (Impulsivity) & 0.37 & 0.60 & 1.79 & 0.42 \\
\hline C5 (Unresponsive to treatment) & 0.26 & 0.56 & 0.32 & 0.58 \\
\hline Total Clinical* & 4.26 & 1.45 & 7.21 & 0.92 \\
\hline R1 (Plans lack feasibility) & 0.58 & 0.69 & 1.16 & 0.76 \\
\hline R2 (Exposure to destabilizers) & 1.00 & 0.58 & 1.68 & 0.48 \\
\hline R3 (Lack of personal support) & 0.32 & 0.58 & 0.74 & 0.73 \\
\hline R4 (Non-compliance with remediation attempts) & 0.74 & 0.65 & 1.42 & 0.69 \\
\hline R5 (Stress) & 0.58 & 0.69 & 1.37 & 0.60 \\
\hline Total Risk Management* & 3.21 & 1.58 & 6.37 & 1.42 \\
\hline Total HCR-20* & 13.37 & 3.55 & 24.89 & 2.98 \\
\hline
\end{tabular}

HCR-20 = Historical, Clinical, and Risk Management 20; SD = standard deviation.

$* t$-test between two independent groups (nonviolent vs. violent) showing statistical significance: $p<0.001$. 
Twelve of the HCR-20 items contributed to the identification of violent and nonviolent patient groups: C4 (impulsivity), H1 (previous violence), R5 (stress), $\mathrm{H} 2$ (young age at first violent incident), H3 (relationship instability), and $\mathrm{H} 5$ (substance use problems) at $\mathrm{p}<$ 0.01 ; H7 (psychopathy), H8 (early maladjustment), C2 (negative attitudes), C1 (lack of insight), R1 (plans lack feasibility), and R3 (lack of personal support) at $p<$ 0.05 (Table 3). Items $\mathrm{H6}$ (major mental illness) and C3 (active symptoms of major mental illness) showed equal scores in the two groups (Table 2).

MOAS scores did not detect severe aggression in the participants (Table 4). Verbal aggression scores were similar in the two groups, and self-aggression was not reported. The internal consistency of MOAS was satisfactory for both aggression against property and physical aggression ( $a=0.75$ and 0.76 , respectively) (Table 4 ).

Table 5 presents the sociodemographic data of the sample. Mean age for the sample was $35.1 \pm 13.6$ years, $92.1 \%$ had no prior criminal record, $76 \%$ were single, $44 \%$ had less than 8 years of schooling, $74 \%$ were black, and $71 \%$ had no children. The majority of the overall sample had a history of psychoactive substance use, without statistically significant differences between the two groups. The violent patient group showed a higher and statistically significant prevalence of current psychoactive substance use. The most reliable items in distinguishing between violent and nonviolent patient groups were: previous admission with or without violent behavior, agreement with treatment, and history of previous psychiatric treatment.

\section{Discussion}

The HCR-20 proved useful for identifying aggressive behavior in patients with schizophrenia and acute need for inpatient psychiatric care. The literature shows similar results. 7,16,22,23 However, the comparison of our results was limited due to the scarcity of empirical research conducted in general psychiatric hospitals with a similar methodology and detailed HCR-20 scores. $7,11,15,16,20,24$

In summary, the HCR-20 items that most helped differentiate between violent and nonviolent patient groups were, in order: C4 (impulsivity), H1 (previous violence), R5 (stress), H2 (young age at first violent incident), $\mathrm{H} 3$ (relationship instability), and H5 (substance

Table 3 - Statistical description of HCR-20 items, by group*

\begin{tabular}{|c|c|c|c|c|c|c|c|c|c|}
\hline & \multicolumn{4}{|c|}{ Nonviolent } & \multicolumn{4}{|c|}{ Violent } & \multirow[b]{3}{*}{$x^{2}$} \\
\hline & \multicolumn{2}{|c|}{ Absent } & \multicolumn{2}{|c|}{ Present } & \multicolumn{2}{|c|}{ Absent } & \multicolumn{2}{|c|}{ Present } & \\
\hline & $\mathbf{n}$ & $\%$ & $\mathbf{n}$ & $\%$ & $\mathbf{n}$ & $\%$ & $\mathbf{n}$ & $\%$ & \\
\hline H1 (Previous violence) & 13 & 68.4 & 6 & 31.5 & 1 & 5.3 & 18 & 94.8 & $16.2^{\dagger}$ \\
\hline $\mathrm{H} 2$ (Young age at first violent incident) & 17 & 89.5 & 2 & 10.5 & 8 & 42.1 & 11 & 57.9 & $9.4^{+}$ \\
\hline H3 (Relationship instability) & 13 & 68.4 & 6 & 31.6 & 4 & 21.1 & 15 & 78.9 & $8.6^{+}$ \\
\hline H4 (Employment problems) & 6 & 31.6 & 13 & 68.4 & 6 & 31.6 & 13 & 68.4 & - \\
\hline H5 (Substance use problems) & 13 & 68.4 & 6 & 31.6 & 5 & 26.3 & 14 & 73.6 & $6.7^{+}$ \\
\hline H6 (Major mental illness) & 0 & 0 & 19 & 100 & 0 & 0 & 19 & 100 & - \\
\hline H7 (Psychopathy) & 19 & 100 & 0 & 0 & 14 & 73.7 & 5 & 26.3 & $5.7^{\ddagger}$ \\
\hline H8 (Early maladjustment) & 19 & 100 & 0 & 0 & 12 & 63.2 & 7 & 36.8 & $5.7^{\ddagger}$ \\
\hline H9 (Personality disorder) & 19 & 100 & 0 & 0 & 18 & 94.7 & 1 & 5.3 & 1.0 \\
\hline H10 (Prior supervision failure) & 3 & 15.8 & 16 & 84.2 & 0 & 0 & 19 & 100 & $3.2^{\S}$ \\
\hline C1 (Lack of insight) & 4 & 21.1 & 15 & 78.9 & 0 & 0 & 19 & 100 & $4.4^{\ddagger}$ \\
\hline C2 (Negative attitudes) & 7 & 36.8 & 12 & 63.2 & 1 & 5.3 & 18 & 94.7 & $5.7^{\ddagger}$ \\
\hline C3 (Active symptoms) & 0 & 0 & 19 & 100 & 0 & 0 & 19 & 100 & - \\
\hline C4 (Impulsivity) & 13 & 68.4 & 6 & 31.6 & 0 & 0 & 19 & 100 & $19.7^{+}$ \\
\hline C5 (Unresponsive to treatment) & 15 & 78.9 & 4 & 21.1 & 14 & 73.5 & 5 & 26.4 & 0.14 \\
\hline R1 (Plans lack feasibility) & 10 & 52.6 & 9 & 47.3 & 4 & 21.1 & 15 & 78.9 & $4.0^{\ddagger}$ \\
\hline R2 (Exposure to destabilizers) & 3 & 15.8 & 16 & 84.2 & 0 & 0 & 19 & 100 & $3.2^{\S}$ \\
\hline R3 (Lack of personal support) & 14 & 73.7 & 5 & 26.3 & 8 & 42.1 & 11 & 57.9 & $3.8^{\ddagger}$ \\
\hline R4 (Non-compliance with remediation attempts) & 7 & 36.8 & 12 & 63.2 & 2 & 10.5 & 17 & 89.5 & $3.6^{\S}$ \\
\hline R5 (Stress) & 10 & 52.6 & 9 & 47.3 & 1 & 5.3 & 18 & 94.7 & $10.3^{+}$ \\
\hline
\end{tabular}

HCR-20 = Historical, Clinical, and Risk Management 20

* Absent $=$ score 0 ; Present $=$ scores 1 and 2 .

${ }^{+} \mathrm{p}<0.01 ;{ }^{\ddagger} \mathrm{p}<0.05 ;{ }^{\S} \mathrm{p}<0.1$. 
use problems) ( $\mathrm{p}<0.01$ ). Items $\mathrm{H7}$ (psychopathy), $\mathrm{H} 8$ (early maladjustment), C2 (negative attitudes), C1 (lack of insight), R1 (plans lack feasibility), and R3 (lack of personal support) showed lower statistical significance ( $p<0.05$ ) (Table 3). Items H6 (major mental illness) and C3 (active symptoms of major mental illness) showed equal scores in the two groups (Table 2).

We observed the highest internal consistency when using all three HCR-20 subscales together ( $a=$ 0.82 ). When used independently, alpha values were 0.73 (Historical), 0.57 (Risk Management), and 0.33
(Clinical). Telles et al. found similar results for the HCR20 as a whole ( $a=0.82$ ), while internal consistency was slightly lower for the Historical subscale ( $a=0.63$ ) and higher for the Risk Management (0.69) and Clinical (0.51) subscales. ${ }^{15}$ This evidence adds reliability to the total HCR-20 score and to the supplementary role of subscale and item analysis. $3,7,8,11,14,15,21$

In one cross-sectional study involving NGRI participants (79\% with a diagnosis of schizophrenia), mean total HCR-20 scores were 22.62 \pm 5.76 , vs. $23.69 \pm 5.94$ in individuals released from forensic

Table 4 - MOAS statistical description

\begin{tabular}{lcccc}
\hline & Absent & Present & Mean & SD \\
\hline VA0 & 34 & 4 & 0.11 & 0.31 \\
VA1 & 5 & 33 & 0.87 & 0.34 \\
VA2 & 10 & 28 & 1.47 & 0.89 \\
VA3 & 21 & 17 & 1.34 & 1.51 \\
VA4 & 35 & 3 & 0.32 & 1.09 \\
Total Verbal Aggression & & & 4.00 & 2.61 \\
& & & 0.50 \\
AAP0 & 17 & 21 & 0.55 & 0.50 \\
AAP1 & 22 & 16 & 0.42 & 0.94 \\
AAP2 & 26 & 12 & 0.63 & 1.29 \\
AAP3 & 29 & 9 & 0.71 & 0.91 \\
AAP4 & 36 & 2 & 0.21 & 2.78 \\
Total Aggression Against Property & & & 1.97 & 0.51 \\
PA0 & & & & 0.51 \\
PA1 & 19 & 19 & 0.40 & 1.01 \\
PA2 & 20 & 18 & 1.00 & 1.29 \\
PA3 & 19 & 19 & 0.71 & 0.91 \\
PA4 & 29 & 9 & 0.21 & 2.86 \\
Total Physical Aggression & 36 & 2 & & \\
MOAS & & & & 17.61 \\
\hline
\end{tabular}

MOAS = Modified Overt Aggression Scale $;$ SD = standard deviation .

Table 5 - Sociodemographic data

\begin{tabular}{|c|c|c|c|c|c|}
\hline & \multicolumn{2}{|c|}{ Nonviolent group } & \multicolumn{2}{|c|}{ Violent group } & \multirow[b]{2}{*}{$\chi^{2}$} \\
\hline & Yes, n (\%) & No, n (\%) & Yes, n (\%) & No, n (\%) & \\
\hline Current alcohol/drug use & $03(15.8)$ & $16(84.2)$ & $8(42.1)$ & $11(57.9)$ & $3.199 *$ \\
\hline Previous alcohol/drug use & $09(47.4)$ & $10(52.6)$ & $13(72.2)$ & $05(27.8)$ & 2.369 \\
\hline Agreement with treatment & $13(68.4)$ & $06(31.6)$ & $05(26.3)$ & $14(73.7)$ & $6.756^{*}$ \\
\hline Insight about disorder & $15(78.9)$ & $04(21.1)$ & $10(52.6)$ & $09(47.4)$ & $2.923 *$ \\
\hline Previous admission with violent behavior & $08(42.1)$ & $11(57.9)$ & $19(100)$ & $0(-)$ & $15.481 *$ \\
\hline Previous admission without violent behavior & $14(73.4)$ & $05(26.3)$ & $08(42.1)$ & $11(57.9)$ & $3.886^{*}$ \\
\hline Psychiatric treatment at time of admission & $11(57.9)$ & $08(42.1)$ & $14(73.7)$ & $05(26.3)$ & 1.052 \\
\hline Previous psychiatric treatment & $04(21.1)$ & 15 (78.9) & $19(100)$ & $0(-)$ & $4.471 *$ \\
\hline Physical or sexual aggression in childhood & $04(21.1)$ & $15(78.9)$ & $06(31.6$ & $13(68.4)$ & 0.543 \\
\hline Source income & $09(47)$ & $10(52.6)$ & $05(26.3)$ & $14(73.7)$ & 1.81 \\
\hline
\end{tabular}

$* \mathrm{p}<0.05$. 
psychiatric hospitals and $21.54 \pm 5.6$ in those released from general psychiatric hospitals. ${ }^{7}$ In a prospective study with NGRI participants released to the community, the mean total HCR-20 score was 21.54 6.7 in the violent patient group. ${ }^{13}$ Our higher values for mean total HCR-20 score in the violent patient group (24.89 \pm 2.98$)$ could be explained by the different timing of evaluation (acute psychotic symptoms at the time of psychiatric admission).

HCR-20 subscale analysis is complementary in VRA. ${ }^{3}$ In this sense, there is no consensus in the literature regarding subscale analysis. ${ }^{10,12,21,22}$ The Clinical and Risk Management subscales appear to be more reliable in settings of institutional violence. ${ }^{10,22}$ Studies on the risk of repeat offenses by NGRI patients point to higher reliability of the Historical and Clinical subscales. ${ }^{12,21}$ This evidence emphasizes the influence of factors like timing of instrument application, setting, and study methodology on HCR-20 scores.

In our study, the mean score obtained for the Historical subscale was $8.61 \pm 3.48$, with mean subtotal scores of $5.89 \pm 1.85$ and $11.32 \pm 2.45$ in the nonviolent and violent patient groups, respectively (Table 2 ). In a prospective study with NGRI individuals (70.8\% with schizophrenia) released from forensic psychiatric hospitals, the mean Historical subscale score was $13.74 \pm 4.42$. The mean score for the violent patient group was $14.53 \pm 3.76$, compared to $12.71 \pm 4.52$ for the non-reoffending group. ${ }^{25}$ These data suggest that there is a subgroup of individuals with a diagnosis of schizophrenia that are potentially more prone than others to violent behavior. ${ }^{25}$

In a seven-year prospective cohort of NGRI patients with schizophrenia released from forensic institutions, a cutoff of 12 on the Historical subscale score showed sensitivity of 0.61 and specificity of 0.80 .12 In our study, the mean score in this subscale $11.32 \pm 2.45$ was similar to this suggested cutoff point. Our results were also similar on items $\mathrm{H} 1$ (previous violence), H2 (young age at first violent incident), and H5 (substance abuse problems) (Table 3). ${ }^{12}$ Despite a possible contribution to the origin of the aggressive behavior, item $\mathrm{H} 10$ (prior supervision failure) did not help differentiate between the violent and nonviolent groups (Table 3). Items $\mathrm{H7}$ (psychopathy) and $\mathrm{H} 8$ (early maladjustment) are frequently more significant in NGRI populations. ${ }^{12,15}$

In the Brazilian validation of the HCR-20, the mean score obtained on the Historical subscale was $12.35 \pm 3.89 .{ }^{15}$ Our results showed a similar mean score (Table 2). The Clinical subscale failed to show satisfactory internal consistency in our study ( $\mathrm{a}=$ $0.33)$, although the literature shows better results. ${ }^{15,24}$ McNiel et al. suggest a cutoff point of 7 for violent behavior, with sensitivity and specificity of 0.62 and 0.80 , respectively. ${ }^{16}$ In our study, the mean score on the Clinical subscale in the violent patient group was $7.21 \pm 0.92$ (Table 2).

Considering the violent and nonviolent patient groups separately, item C4 (impulsivity) was the single most reliable item, corroborating previous studies (Table 3). ${ }^{10,15,22,23}$ According to Telles et al., items C2 (negative attitudes), C5 (unresponsive to treatment), C4 (impulsivity), and C1 (lack of insight) were the most reliable for VRA. We found similar results for items C1 (lack of insight), C2 (negative attitudes), and C4 (impulsivity) (Table 3). ${ }^{15}$ In our study, item C3 (active symptoms of major mental illness) did not reach statistical significance (Tables 2 and 3), as also observed in Telles et al. ${ }^{15}$

In a retrospective study with NGRI participants admitted to forensic institutions, the Clinical and Risk Management subscales, used together, were more reliable for predicting institutional violence. ${ }^{26}$ A follow-up study found similar results: mean scores on the Clinical and Risk Management subscales were $5.40 \pm 0.32$ and $7.15 \pm 0.25$ in the violent patient group, and $3.98 \pm 0.18$ and $6.05 \pm 0.16$ in the nonviolent patient group, respectively. ${ }^{23}$ Our results differ slightly regarding Clinical subscale scores in the violent patient group (Table 2).

The Risk Management subscale shows a strong association with violent behavior in NGRI individuals. ${ }^{7,15}$ In the Brazilian validation of the HCR-20, the Risk Management subscale showed higher internal consistency ( $a=0.69$ ) compared to the Historical ( $a$ $=0.63)$ and Clinical subscales $(a=0.53) .{ }^{15} \mathrm{~A}$ crosssectional study also demonstrated the usefulness of Risk Management items for predicting reconviction in NGRI patients. ${ }^{7}$ Other studies found similar results. ${ }^{13,26}$

Our results suggest that the characteristics explored by the Risk Management subscale are probably relevant in both NGRI individuals and the general psychiatric population.7,13,26 Items R5 (stress) and R3 (lack of personal support) showed the highest statistical significance among the items in the Risk Management subscale (Table 3 ). The fact that we sampled participants that lived in the same neighborhood may have influenced this subscale's score.

Research on VRA has used different methodologies and psychometric instruments to describe aggressive behavior. ${ }^{4,5}$ However, few studies have used the HCR20 and MOAS together in the same population. 5,19,20 As in our study, Telles et al. found a higher prevalence of verbal aggression (57\%) in the total sample. ${ }^{20}$ Prevalence rates for self-aggression and aggression against property were below $5 \% .^{20}$ 
Sociodemographic data did not help distinguish between violent and nonviolent patient groups, in contrast with HCR-20 results. The lack of statistically significant differences between groups in items like source of income, childhood physical/sexual abuse, and psychiatric treatment at the time of admission, along with the presence of family support (inclusion criteria), suggest the homogeneity of our sample concerning these characteristics. The statistically significant difference between the groups in current alcohol/drug use and history of admission for violent behavior is consistent with the literature. ${ }^{10,12,15}$

Our small sample size (38) limits the generalization of results, which refer specifically to patients with schizophrenia and acute need for psychiatric admission in Rio de Janeiro. Also, the availability of only one researcher may have limited the reliability of results.

\section{Conclusion}

The HCR-20 demonstrated efficacy in identifying and distinguishing between violent and nonviolent patients with schizophrenia admitted to a general psychiatric hospital. The scarcity of studies on nonviolent patients limits the comparison of our results. In our study, HCR-20 showed more reliable results in the nonviolent patient group. The results could be useful for identifying potential violent and nonviolent patients in clinical psychiatric settings. Further research could benefit from this approach.

\section{References}

1. Monahan J, Steadman HJ, Silver E, Appelbaum OS, Robbins PC, Mulvey EP, et al. Rethinking risk assessment: the MacArthur study of mental disorder and violence. New York: Oxford University Press; 2001.

2. Douglas KS, Guy LS, Hart SD. Psychosis as a risk factor for violence to others: a meta-analysis. Psychol Bull. 2009;135:679706.

3. Webster CD, Douglas KS, Eaves D, Hart SD. HCR-20 assessing risk for violence version 2. Burnaby: Mental Health, Law, and Policy Institute, Simon Fraser University; 1997.

4. Singh JP, Grann M, Fazel S. A comparative study of violence risk assessment tools: a systematic review and metaregression analysis of 68 studies involving 25,980 participants. Clin Psychol Rev. 2011;31:499-513.

5. Singh JP, Serper M, Reinharth J, Fazel S. Structured assessment of violence risk in schizophrenia and other psychiatric disorders: a systematic review of the validity, reliability, and item content of 10 available instruments. Schizophr Bull. 2011;37:899-912.

6. Gray NS, Taylor J, Snowden RJ. Predicting violence using structured professional judgment in patients with different mental and behavioral disorders. Psychiatry Res. 2011;187:248-53.

7. Crocker a G, Côté G. Evolving systems of care: Individuals found not criminally responsible on account of mental disorder in custody of civil and forensic psychiatric services. Eur Psychiatry. 2009;24:356-64.
8. Daffern M. The predictive validity and practical utility of structured schemes used to assess risk for aggression in psychiatric inpatient settings. Aggress Violent Behav. 2007;12:116-30.

9. Nilsson T, Wallinius M, Gustavson C, Anckarsäter $H$, Kerekes $\mathrm{N}$. Violent recidivism: a long-time follow-up study of mentally disordered offenders. PLoS One. 2011;6:e25768.

10. Fullam $\mathrm{R}$, Dolan $\mathrm{M}$. The criminal and personality profile of patients with schizophrenia and comorbid psychopathic traits. Pers Individ Dif. 2006;40:1591-602.

11. Doyle M, Carter S, Shaw J, Dolan M. Predicting community violence from patients discharged from acute mental health units in England. Soc Psychiatry Psychiatr Epidemiol. 2012;47:62737.

12. Tengström a. Long-term predictive validity of historical factors in two risk assessment instruments in a group of violent offenders with schizophrenia. Nord J Psychiatry. 2001;55:243-9.

13. Gray NS, Snowden RJ, MacCulloch S, Phillips H, Taylor J, MacCulloch MJ. Relative efficacy of criminological, clinical, and personality measures of future risk of offending in mentally disordered offenders: a comparative study of HCR-20, PCL:SV and OGRS. J Consult Clin Psychol. 2004;72:523-30.

14. Gray NS, Fitzgerald S, Taylor J, Macculloch MJ, Snowden RJ. Predicting future reconviction in offenders with intellectual disabilities: the predictive efficacy of VRAG, PCL-SV, and the HCR20. Psychol Assess. 2007;19:474-9.

15. Telles LE de B, Day VP, Folino JO, Taborda JGV. Reliability of the Brazilian version of HCR-20 Assessing Risk for Violence. Rev Bras Psiquiatr. 2009;31:253-6.

16. McNiel DE, Gregory AL, Lam JN, Binder RL, Sullivan GR. Utility of decision support tools for assessing acute risk of violence. J Consult Clin Psychol. 2003;71:945-53.

17. American Psychiatric Association. Diagnostic and Statistical Manual of Mental Disorders, Fourth Edition, Text Revision (DSMIV-TR). Arlington: American Psychiatric Publishing; 2000.

18. Del-Ben CM, Vilela JA, Crippa JAS, Hallak JEC, Labate CM, Zuardi AW. Reliability of the Structured Clinical Interview for DSM-IV Clinical Version translated into Portuguese. Rev Bras Psiquiatr. 2001;23:7-10

19. Oliver PC, Crawford MJ, Rao B, Reece B, Tyrer P. Modified Overt Aggression Scale (MOAS) for people with intellectual disability and aggressive challenging behavior: a reliability study. J Appl Res Intellect Disabil. 2007;20:368-72.

20. Telles LE de B, Folino JO, Taborda JGV. Incidência de conduta violenta e antissocial em população psiquiátrica forense. Rev Psiquiatr Rio Gd Sul. 2009;33:3-7.

21. Telles LE de B, Folino JO, Taborda JGV. Accuracy of the Historical, Clinical and Risk Management Scales (HCR-20) in predicting violence and other offenses in forensic psychiatric patients in Brazil. Int J Law Psychiatry. 2012;35:427-31.

22. Dumais A, Potvin S, Joyal C, Allaire J-F, Stip E, Lesage A, et al. Schizophrenia and serious violence: a clinical-profile analysis incorporating impulsivity and substance-use disorders. Schizophr Res. 2011;130:234-7.

23. Mcdermott BE, Quanbeck CD, Busse D, Yastro K, Scott CL. The accuracy of risk assessment instruments in the prediction of impulsive versus predatory aggression. 2008;777:759-77.

24. O'Shea LE, Mitchell AE, Picchioni MM, Dickens GL. Moderators of the predictive efficacy of the Historical, Clinical and Risk Management-20 for aggression in psychiatric facilities: Systematic review and meta-analysis. Aggress Violent Behav. 2012;18:25570.

25. Ho $H$, Thomson L, Darjee R. Violence risk assessment: the use of the PCL-SV, HCR-20, and VRAG to predict violence in mentally disordered offenders discharged from a medium secure unit in Scotland. J Forens Psychiatry Psychol. 2009;20:523-41.

26. Dolan M, Blattner R. The utility of the Historical Clinical Risk-20 Scale as a predictor of outcomes in decisions to transfer patients from high to lower levels of security-a UK perspective. BMC Psychiatry. 2010;10:76.

\section{Correspondence:}

Leonardo Fernandez Meyer

Rua Assunção 490/603, Botafogo

22251-030 - Rio de Janeiro, RJ - Brazil

E-mail: Ifm1205@gmail.com 